\title{
EFEITO DE TEMPERATURAS SOBRE A GERMINAÇÃO DE SEMENTES DE ERVA-DE-TOURO (Tridax procumbens )'
}

\author{
Effect of Temperatures on the Germination of Tridax procumbens Seeds
}

\author{
GUIMARÃES, S.C. ${ }^{2}$, SOUZA, I.F. ${ }^{3}$ e PINHO, E.V.R.V. ${ }^{3}$
}

\begin{abstract}
RESUMO - A erva-de-touro (Tridax procumbens) é uma planta daninha de importância crescente no Brasil. Visando conhecer o efeito de temperaturas constantes sobre a germinação de suas sementes, foi conduzido um experimento em câmaras de germinação, com 12 horas diárias de luz, avaliando-se, em três lotes, as temperaturas de $15,20,25,30,35$ e $40{ }^{\circ} \mathrm{C}$. A unidade experimental foi constituída por uma caixa plástica transparente $(11,5 \times 11,5 \times 3,5 \mathrm{~cm})$, com 100 aquênios dispostos entre duas folhas de papel mata-borrão, umedecidas com água destilada. A germinação final das sementes da erva-de-touro foi superior nas temperaturas de 25,30 e $35{ }^{\circ} \mathrm{C}$, com maior velocidade a $30{ }^{\circ} \mathrm{C}$ e melhor distribuição no tempo a $35^{\circ} \mathrm{C}$. No lote com melhor desempenho, ocorreram $94,5 \%$ de germinação a $25{ }^{\circ} \mathrm{C}, 93,4 \%$ a $30{ }^{\circ} \mathrm{C}$ e $92,0 \%$ a $35{ }^{\circ} \mathrm{C}$, com índices de velocidade de germinação de 14,2; 17,4; e 12,0, respectivamente. Nas outras temperaturas, a germinação final foi muito baixa, com valores médios, para os três lotes, de $1,3 \%$ a $15{ }^{\circ} \mathrm{C}, 5,4 \%$ a $20{ }^{\circ} \mathrm{C}$ e $3,4 \%$ a $40{ }^{\circ} \mathrm{C}$. Num tratamento adicional, em condições ambientais não-controladas (temperatura ambiente oscilando entre $20{ }^{\circ} \mathrm{C}$ e $28{ }^{\circ} \mathrm{C}$ ), a germinação foi também muito baixa $(1,5 \%)$. Sementes dos tratamentos de $15{ }^{\circ} \mathrm{C}$ e $20^{\circ} \mathrm{C}$, transferidas para $30^{\circ} \mathrm{C}$ após o período experimental, atingiram a germinação máxima do lote, enquanto aquelas do tratamento de $40{ }^{\circ} \mathrm{C}$ perderam de 50 a $80 \%$ de sua viabilidade. Embora em proporção muito pequena, houve ocorrência de germinação até 80 dias após o início do teste. Em temperaturas entre 25 e $35^{\circ} \mathrm{C}$, as sementes da erva-de-touro iniciaram a protrusão raiz primária entre dois e quatro dias após o início da embebição, mesmo quando recém-liberadas da planta-mãe.
\end{abstract}

Palavras-chave: planta daninha, planta medicinal, ecologia da germinação.

\begin{abstract}
The aim of this study was to evaluate the effect of constant temperatures on the seed germination of Tridax procumbens, a weed of increasing importance in Brazil. Germination was carried out with 4 replicates of 100 seeds (achenes) from 3 different samples. Seeds were placed between two layers of blotting-paper, soaked in distilled water inside closed transparent plastic boxes incubated for 12 hours of light per day, at temperatures of 15, 20, 25, 30, 35 and $40{ }^{\circ} \mathrm{C}$. In general, total germination was higher at 25, 30 and $35{ }^{\circ} \mathrm{C}$, with highest germination velocity index at $30^{\circ} \mathrm{C}$, and the best distribution of germination over time at $35{ }^{\circ} \mathrm{C}$. The results from the seed sample with the best germination performance were $94.5 \%$ at $25^{\circ} \mathrm{C}, 93.4 \%$ at $30{ }^{\circ} \mathrm{C}$ and $92 \%$ at $35{ }^{\circ} \mathrm{C}$, with germination velocity index of $14.28,17.43$ and 12 , respectively. The overall germination at other temperatures tested was very low, i.e., $1.3 \%$ at $15{ }^{\circ} \mathrm{C}, 5.4 \%$ at $20{ }^{\circ} \mathrm{C}$ and $3.4 \%$ at $40{ }^{\circ} \mathrm{C}$, as well as in an additional treatment, under alternating temperature at room temperature (temperatures varying from 20 to $28{ }^{\circ} \mathrm{C}$ ). Seeds incubated at 15 and $20^{\circ} \mathrm{C}$ achieved full germination after being transferred to $30{ }^{\circ} \mathrm{C}$, while those incubated at $40{ }^{\circ} \mathrm{C}$ lost 50 to $80 \%$ of their viability. Although in small proportions, some seeds germinated up to 80 days of imbibition. Primary root protrusion initiated after 2 to 4 days of imbibition at 25, 30 and $35^{\circ} \mathrm{C}$, even when seeds had been recently shed from the mother plant.
\end{abstract}

Key words: weed, medicinal plant, germination ecology.

Recebido para publicação em 26/12/99 e na forma revisada em 11/2/2000.

Prof. DFF/FAMEV/UFMT. 78060-900, Cuiabá, MT. ${ }^{3}$ Prof. DAG/UFLA. 37200-000 Lavras, MG. 


\section{INTRODUÇÃO}

Erva-de-touro (Tridax procumbens) é uma planta daninha da família Asteraceæ, originária da América Central, de onde se difundiu para outras regiões, como América do Sul e África (Kissmann \& Groth, 1992), América do Norte (Zimdahl, 1983) e Ásia (Shetty et al., 1982). No Brasil, é relatada como freqüente nas regiões Sudeste e Centro-Oeste, infestando pastagens, beiras de estradas, terrenos desocupados e áreas urbanas (Kissmann \& Groth, 1992; Lorenzi, 1991). Não obstante, nos últimos 10 anos, esta espécie teve disseminação muito rápida nas áreas de culturas anuais, nos cerrados do Centro-Oeste brasileiro. A magnitude deste crescimento pode ser avaliada em Mato Grosso, estado onde a espécie aparece atualmente em grandes infestações, embora, no início da década de 80 (Guimarães \& Frutuoso, 1983), sua ocorrência fosse pouco expressiva. Em 1994 foi relatada como planta daninha nas regiões Norte, Sul e Triângulo de Minas Gerais (Bacelar, 1994), havendo também citação de ocorrência em áreas não-agrícolas da Argentina (Botta \& Cabrera, 1986).

$\mathrm{Na}$ Índia, onde tem ampla distribuição, a erva-de-touro é estudada como planta medicinal (Saraf et al., 1992; Udupa et al., 1991; Verma \& Gupta, 1988), e no Brasil, recentemente, tem sido também pesquisada com esse enfoque (Cerqueira, 1999).

Embora possa se perenizar, a erva-de-touro, normalmente, tem apresentado ciclo anual nas lavouras de soja e milho, nos cerrados do Brasil Central. Ela se reproduz por sementes, e muito pouco se conhece sobre a ecologia da germinação destes órgãos reprodutivos. $\mathrm{O}$ domínio desse conhecimento é um importante instrumento de manejo, porque o controle da germinação das sementes é o que garante a persistência no ambiente agrícola das plantas daninhas de ciclo anual (Egley, 1995; Karssen e Bouwmeester, 1992).

A temperatura é um fator ecológico com grande influência no processo de germinação de sementes, determinando seus limites e a taxa de sua ocorrência, agindo também na quebra e indução de dormência (Bewley \& Black, 1994). Alguns estudos sobre germinação e temperatura foram realizados em erva-detouro, mas nenhum deles com especificidade e método suficientes para gerar informações abrangentes. Sharma (1987), com base em uma única avaliação aos 10 dias, verificou que sementes de Tridax procumbens germinaram numa faixa de temperatura de 15 a $35^{\circ} \mathrm{C}$, com um máximo a $25{ }^{\circ} \mathrm{C}(32 \%)$, não havendo germinação nem a 10 nem a $40{ }^{\circ} \mathrm{C}$. Marks \& Akosim (1984) obtiveram melhores germinações a $27^{\circ} \mathrm{C}$, muito superiores àquelas registradas para 30 ou $35{ }^{\circ} \mathrm{C}$. Popay (1974) obteve $84 \%$ de germinação em sementes de erva-de-touro recém-liberadas, quando coletadas no mês de janeiro, e $12 \%$ quando coletadas em agosto, realizando o teste em condições não-controladas (21 a $29{ }^{\circ} \mathrm{C}$ em janeiro e 19 a $25{ }^{\circ} \mathrm{C}$ em agosto). Nesse mesmo estudo, este autor verificou que não houve germinação a $4{ }^{\circ} \mathrm{C}$, mesmo quando se possibilitavam cinco horas diárias de temperaturas entre 18 e $25{ }^{\circ} \mathrm{C}$, e que a $30^{\circ} \mathrm{C}$ o desempenho foi melhor do que em temperatura ambiente (19 a $\left.25^{\circ} \mathrm{C}\right)$. Em outro trabalho, usando sementes na superfície de vasos em ambiente aberto, Popay $(1975,1976)$ verificou que a emergência aumentava após o início das chuvas, mesmo quando os vasos eram irrigados na época seca, fato que o autor supôs se dever à redução da temperatura ambiente neste período, não fazendo, no entanto, referência a valores.

O objetivo deste trabalho foi avaliar o efeito de temperaturas constantes sobre o comportamento germinativo da erva-de-touro.

\section{MATERIAL E MÉTODOS}

\section{Origem dos aquênios}

Os aquênios foram coletados em plantas cultivadas em canteiros experimentais no Departamento de Agricultura da Universidade Federal de Lavras (DAG/UFLA), a partir de material original provindo de área agrícola no município de Rondonópolis, Estado de Mato Grosso, de uma população há vários anos infestando culturas anuais (soja e milho). Os capítulos eram colhidos quando havia pelo menos um aquênio com papilho aberto e deixados secar à sombra, para facilitar o desprendimento dos frutos. Após a retirada dos capítulos, os aquênios passavam por uma seleção visual, descartando-se os provenientes de flores femininas e aqueles com evidência de não possuírem 
sementes (de coloração branca) ou de tê-las com má formação (finos).

\section{Procedimento experimental}

Três lotes de sementes foram colocados para germinar no Laboratório de Sementes do DAG/UFLA, em temperaturas constantes de $10,15,20,25,30,35$ e $40{ }^{\circ} \mathrm{C}$. O lote 1 constituiu-se de sementes com 49 a 55 dias de idade (dias após a coleta dos capítulos), sendo essa operação realizada entre 18 e 24 de junho de 1997; no lote 2 as sementes tinham três a seis dias de idade, com coleta entre 6 e 9 de agosto de 1997; e no lote 3 elas tinham idade de um dia, com coleta em 18 de agosto de 1997.

O estudo foi realizado em câmaras de germinação tipo BOD, reguladas para proporcionar as diferentes temperaturas $\left( \pm 0,5^{\circ} \mathrm{C}\right)$, com um regime de luz de 12 horas diárias, usando-se quatro lâmpadas fluorescentes branca fria de $20 \mathrm{~W}$. Cada parcela foi constituída por uma caixa plástica tipo gerbox, com 100 aquênios dispostos entre duas folhas de papel mata-borrão, umedecidas com água destilada até saturação e reumedecidas sempre que necessário. Os tratamentos foram dispostos inteiramente ao acaso e repetidos quatro vezes. O número de sementes germinadas foi contado diariamente até 21 dias após a semeadura, nos lotes 1 e 2 , e até 14 dias, no lote 3. Foram consideradas germinadas as sementes com qualquer estrutura da plântula visível a olho nu. A partir dos dados de germinação diária, foram calculados a germinação até 7,14 e 21 dias (7 e 14 dias para o lote 3), a germinação acumulada durante período, o índice de velocidade de germinação (IVG) (Maguire, 1962) e o número de dias necessários para germinar $50 \%$ dos indivíduos da população $\left(\mathrm{T}_{50}\right)$. Um tratamento adicional foi incluído para avaliar a germinação em condições nãocontroladas, em sala de laboratório, nos lotes 1 e 2. Após o período experimental, todos os tratamentos foram transferidos para $30{ }^{\circ} \mathrm{C}$, em que a germinação continuou sendo avaliada por mais 68 dias, e ao fim deste período verificou-se a viabilidade das sementes não-germinadas pelo teste de tetrazólio.

Os valores de $T_{50}$ foram obtidos a partir das curvas ajustadas para as diferentes temperaturas. A germinação semanal e o IVG foram julgados com base em suas médias, apresentadas com os respectivos erros-padrão. Os dados de germinação acumulada no tempo, em razão da distribuição binomial dos resíduos, foram submetidos à análise, usando a função ligadora canônica logit, com o auxílio da "Proc Genmod" do programa estatístico SAS (SAS Institute Inc., 1992). O estudo dos desdobramentos de temperatura dentro dos lotes foi realizado pelo ajuste das médias à função de distribuição de Weibull (Brown \& Mayer, 1988), usando a "Proc Nlin" do mesmo programa estatístico. A discriminação entre os ajustes das melhores temperaturas foi realizada pelo procedimento descrito por Mead \& Curnow (1983).

\section{RESULTADOS E DISCUSSÃO}

O comportamento germinativo da erva-detouro foi influenciado pela temperatura e pelo lote e houve interação entre temperatura e lote $(\mathrm{p}<0,05)$. A germinação acumulada no tempo, para os três lotes, nas diferentes temperaturas, está apresentada na Figura 1. As médias dos valores observados estão representadas por símbolos marcadores, e as linhas são os ajustes dos dados à função de distribuição de Weibull. O modelo da função utilizada é mostrado na Tabela 1, bem como as estimativas obtidas para os parâmetros e os valores dos coeficientes de determinação $\left(\mathrm{r}^{2}\right)$.

Os lotes diferiram na capacidade germinativa, com valores médios de germinação final, nas três melhores temperaturas, de $73,0 \%$ no lote $1 ; 93,5 \%$ no lote 2 ; e $72,1 \%$ no lote 3 . Estas diferenças refletiram o número de sementes viáveis em cada lote, uma vez que não houve germinações significativas nestes tratamentos quando deixados por mais 68 dias a $30^{\circ} \mathrm{C}$ e também, posteriormente, nenhuma semente viável foi identificada pelo teste de tetrazólio. Por terem sido utilizadas sementes novas, colhidas há menos de dois meses, a diferença de qualidade dos lotes está provavelmente relacionada às condições edafoclimáticas vigentes durante a formação das sementes (Wulff, 1995) e também às possíveis diferenças na seleção dos aquênios em cada lote, uma vez que este processo foi visual e realizado em períodos distintos. 

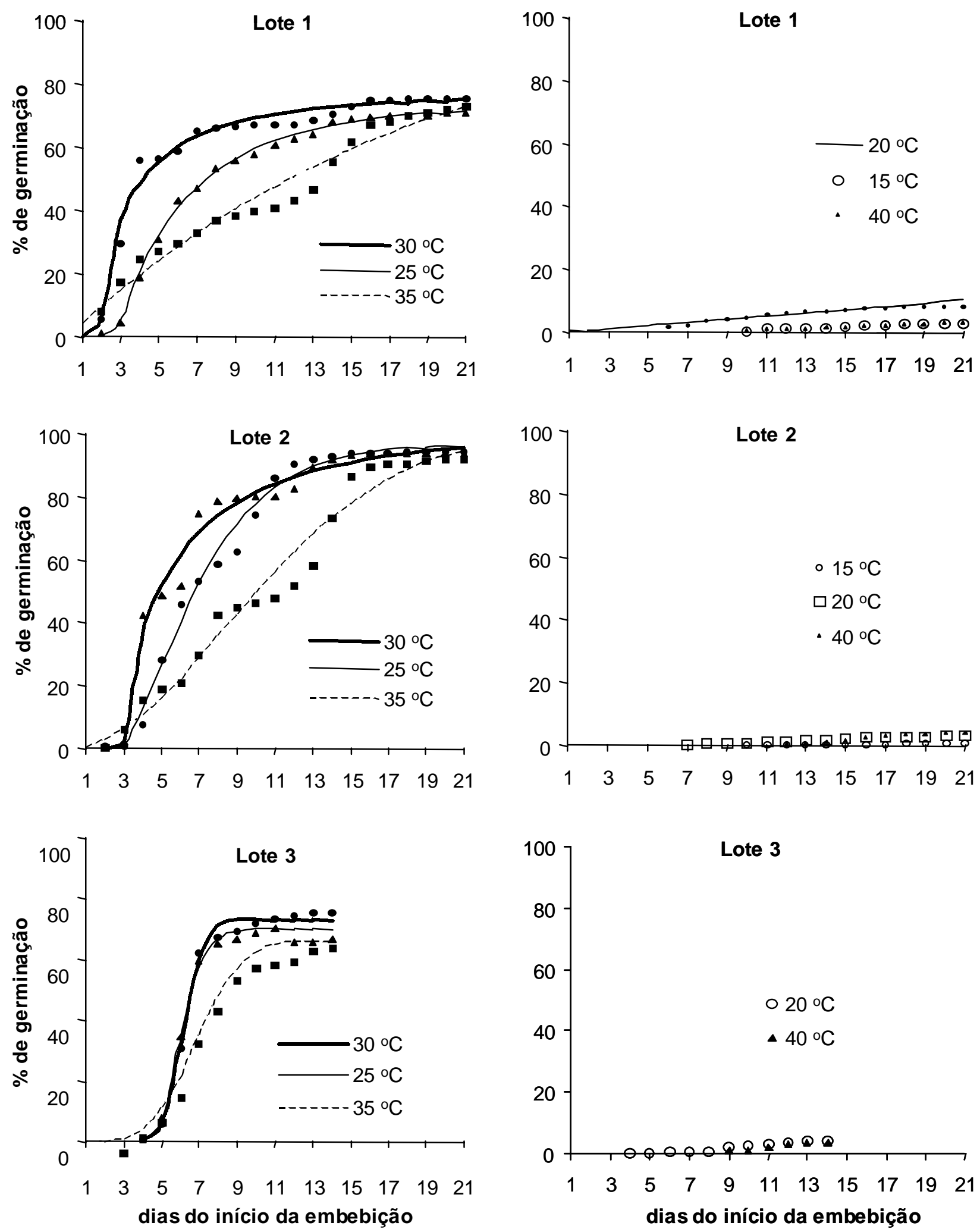

Figura 1 - Germinação acumulada de sementes de erva-de-touro, de três lotes, em diferentes temperaturas. As linhas representam o ajuste dos dados à função de Weibull. Lavras, MG, 1999. 
Tabela 1 - Estimativas dos parâmetros M, k, z e c da função de Weibull, valores do coeficiente de determinação $\left(\mathrm{r}^{2}\right)$ e número de dias para 50\% de germinação (T50), para os três lotes, nas diferentes temperaturas. Lavras, MG, 1999

\begin{tabular}{|c|c|c|c|c|c|c|c|}
\hline Lote & $\mathrm{T}\left({ }^{\circ} \mathrm{C}\right)$ & $\mathrm{M}$ & $\mathrm{k}$ & $\mathrm{Z}$ & $\mathrm{c}$ & $\mathrm{r}^{2}$ & $\mathrm{~T}_{50}$ \\
\hline \multirow{6}{*}{1} & 15 & 3,13 & 0,0680 & 0,000 & 4,957 & 86,71 & $*$ \\
\hline & 20 & 100,00 & 0,0073 & 0,000 & 1,191 & 93,6 & $*$ \\
\hline & 25 & 72,62 & 0,2484 & 2,800 & 0,911 & 98,5 & 7,57 \\
\hline & 30 & 76,12 & 0,4966 & 1,965 & 0,631 & 97,2 & 4,21 \\
\hline & 35 & 100,00 & 0,0607 & 0,000 & 1,093 & 96,4 & 11,78 \\
\hline & 40 & - & - & - & - & - & - \\
\hline \multirow{6}{*}{2} & 15 & - & - & - & - & - & - \\
\hline & 20 & - & - & - & - & - & - \\
\hline & 25 & 96,46 & 0,1986 & 2,800 & 1,373 & 97,5 & 6,81 \\
\hline & 30 & 100,00 & 0,3112 & 2,990 & 0,662 & 97,8 & 4,84 \\
\hline & 35 & 100,00 & 0,0823 & 0,000 & 1,967 & 96,5 & 10,09 \\
\hline & 40 & - & - & - & - & - & - \\
\hline \multirow{6}{*}{3} & 15 & - & - & - & - & - & - \\
\hline & 20 & 3,96 & 0,0930 & 0,000 & 5,970 & 97,9 & $*$ \\
\hline & 25 & 69,47 & 0,5112 & 5,360 & 1,860 & 99,5 & 6,60 \\
\hline & 30 & 73,31 & 0,4428 & 4,197 & 2,350 & 98,9 & 6,59 \\
\hline & 35 & 66,20 & 0,1650 & 1,463 & 3,120 & 99,5 & 8,23 \\
\hline & 40 & 3,77 & 0,0900 & 0,000 & 6,931 & 98,3 & $*$ \\
\hline
\end{tabular}

- Os dados não se ajustaram à função de Weibull. Em todos estes casos a germinação final foi muito baixa.

* A germinação máxima não atingiu 50\%.

Função de Weibull $\longrightarrow \mathrm{Y}=\mathrm{M}\left[1-\mathrm{e}^{-\mathrm{k}(\mathrm{d}-\mathrm{z})^{\mathrm{c}}}\right]$, em que Y é a \% de germinação e d é o número de dias após o início da embebição.

A temperatura teve efeito marcante no comportamento germinativo das sementes da erva-de-touro. A 15,20 e $40{ }^{\circ} \mathrm{C}$ a germinação final foi baixa, com valores médios de $1,5 \%$, 5,4 e $3,4 \%$, respectivamente, não havendo germinação a $15{ }^{\circ} \mathrm{C}$ no lote 3 . Nestas temperaturas, via de regra, o início da germinação ocorreu após seis dias. Os tratamentos a 15 e $20{ }^{\circ} \mathrm{C}$, levados para $30^{\circ} \mathrm{C}$ após o período experimental, atingiram a germinação máxima do lote, enquanto aquele a $40{ }^{\circ} \mathrm{C}$ perdeu de 50 a $80 \%$ na viabilidade de suas sementes (avaliação final pelo teste de tetrazólio). Por outro lado, nas temperaturas de 25,30 e $35^{\circ} \mathrm{C}$ houve germinação de quase todas as sementes viáveis durante o período experimental, com valores médios finais de 79,1, 81,8 e 78,0\%, respectivamente. Nestes tratamentos, a germinação teve início entre dois e quatro dias, sendo mais rápida no lote 1 e nas maiores temperaturas. A comparação do comportamento germinativo entre estas três melhores temperaturas, realizada através do procedimento descrito por
Mead \& Curnow (1983), usando a função de distribuição de Weibull para o ajuste dos dados, mostrou haver diferenças entre cada uma delas, o que permite afirmar que, não obstante a germinação final semelhante, a velocidade do processo foi distinta, sendo mais rápida a $30{ }^{\circ} \mathrm{C}$ e mais bem distribuída no tempo a $35{ }^{\circ} \mathrm{C}$. Os gráficos com os valores da germinação aos 7,14 e 21 dias e do IVG, apresentados na Figura 2, ilustram esse comportamento, onde se verifica também que, no lote 3 , estas diferenças foram menos marcantes, principalmente entre as temperaturas de 25 e $30{ }^{\circ} \mathrm{C}$. Ainda comparando as três melhores temperaturas, observa-se que o número de dias necessários para se atingir 50\% de germinação, mostrado na Tabela 1, foi, em média, menor a $30^{\circ} \mathrm{C}$ e maior a $35{ }^{\circ} \mathrm{C}$, reafirmando as conclusões obtidas na análise das outras variáveis. No lote 3 , o $\mathrm{T}_{50}$ não foi sensivel para distinguir as temperaturas de 25 e $30^{\circ} \mathrm{C}$, uma vez que estas tiveram comportamento semelhante até valores próximos a 60\% de germinação (Figura 1). 


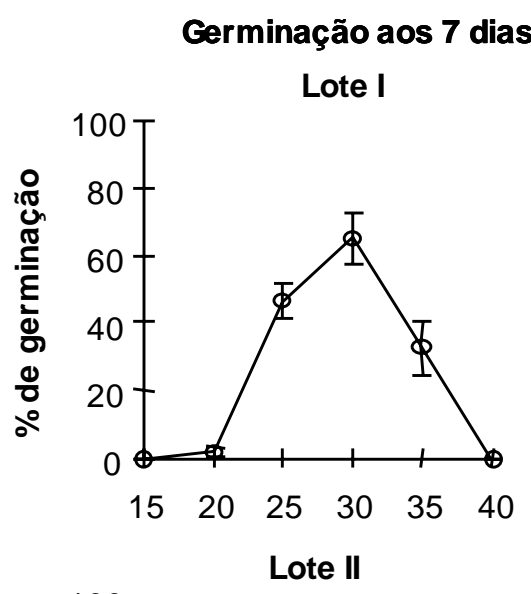

Germinação aos 14 dias

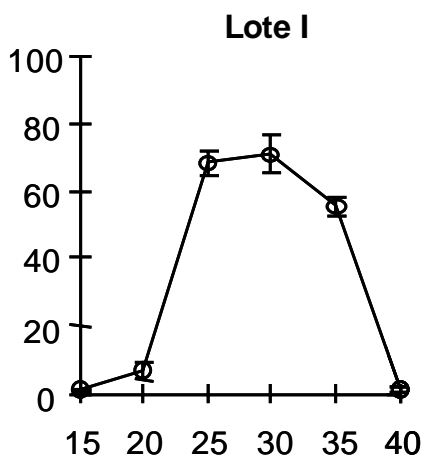

$\begin{array}{llllll}15 & 20 & 25 & 30 & 35 & 40\end{array}$

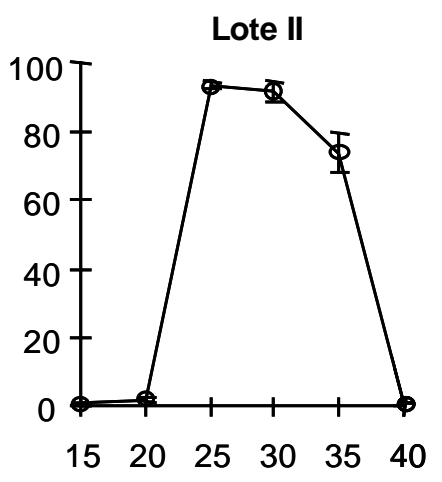

Lote III
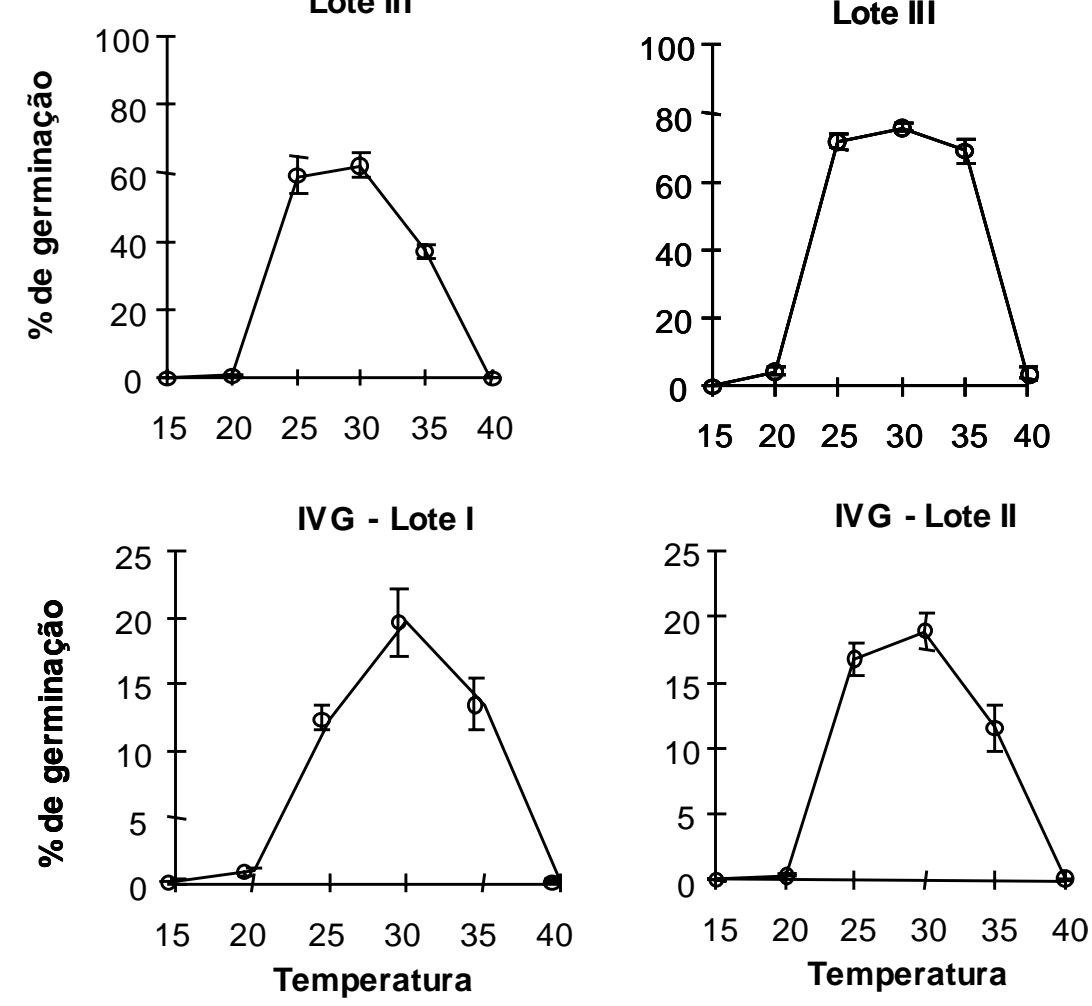

Germinação aos 21 dias

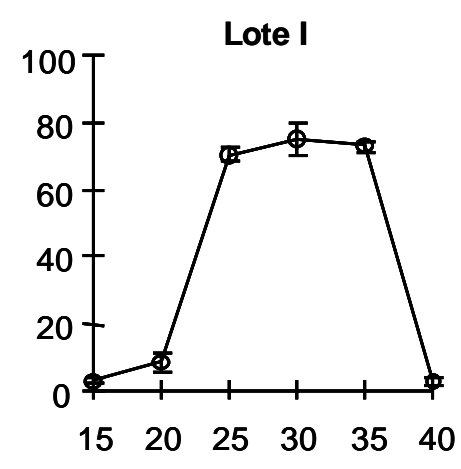

Lote II

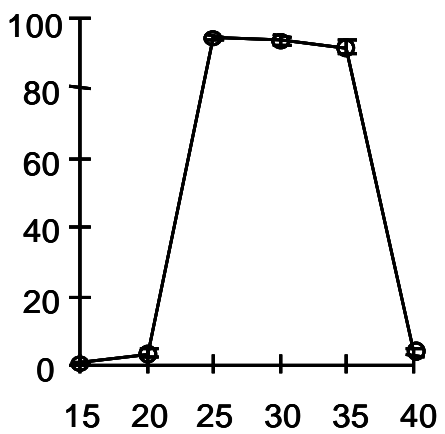

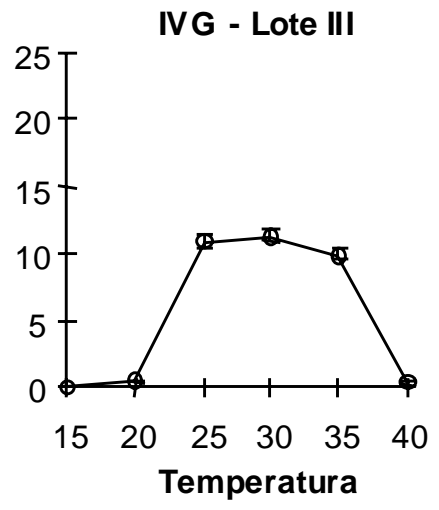

Figura 2 - Germinação de sementes de erva-de-touro, de três lotes, submetidas a diferentes temperaturas, aos 7, 14 e 21 dias, e o índice de velocidade de germinação. As barras representam erro-padrão da média. Lavras, MG, 1999. 
Conforme relatado por Kissmann \& Groth (1992), as sementes da erva-de-touro, em campo, apresentam dormência inicial e germinação escalonada. Em laboratório, sob temperatura favorável e na presença de luz, as sementes tiveram germinação rápida e uniforme, e somente uma fração muito pequena apresentou germinação tardia $(1,21 \%$ depois de 50 dias de embebição). No entanto, em temperatura de $35{ }^{\circ} \mathrm{C}$ (supra-ótima), a velocidade do processo foi reduzida, provocando escalonamento da germinação. Embora não ocorram temperaturas constantes no campo, valores elevados na superfície do solo, durante as horas mais quentes do dia, podem, em parte, responder pela distribuição das emergências no tempo. Adicionalmente, como a permanência das sementes por períodos prolongados em ambiente desfavorável à germinação pode induzir dormência secundária (Bewley \& Black, 1994), é possível que este mecanismo também contribua para a desuniformidade do processo, estratégia comum de sobrevivência em plantas daninhas, que possibilita a distribuição das emergências no tempo e no espaço (Holzner et al., 1982).

O efeito da temperatura na germinação final desta população de erva-de-touro foi diferente daquele observado por outros autores, que trabalharam na África com populações locais. Sharma (1987), na Nigéria, além de obter germinação máxima a $25{ }^{\circ} \mathrm{C}(32 \%)$ e não constatar diferenças entre as temperaturas de 15,30 e $35{ }^{\circ} \mathrm{C}$, verificou que nestas os valores de germinação foram inferiores àqueles obtidos a $20^{\circ} \mathrm{C}$. Marks \& Akosim (1984), também na Nigéria, observaram que a germinação a $27{ }^{\circ} \mathrm{C}$ foi de 2,5 a 3 vezes superior àquelas obtidas nas temperaturas de 30 e $35^{\circ} \mathrm{C}$. Diferenças de comportamento germinativo entre populações já foram verificadas para várias espécies (Baskin \& Baskin, 1998), incluindo a erva-detouro (Ramakrishnan \& Jain, 1967). Por ser uma planta não-domesticada, a erva-de-touro deve apresentar grande diversidade genética, e diferenças na pressão de seleção provavelmente fizeram com que os ecotipos da Nigéria fossem diferentes dos encontrados no Brasil.

A perda de viabilidade ocorrida nas sementes à temperatura de $40{ }^{\circ} \mathrm{C}$, durante o período experimental, é um indicativo de que, em campo, a combinação de umidade com temperaturas muito altas pode se constituir num fator de depleção do banco de sementes de erva-detouro no solo.

Em condições não-controladas, em sala de laboratório, com temperatura ambiental variando entre 20 e $28{ }^{\circ} \mathrm{C}$, a germinação das sementes da erva-de-touro foi de apenas $2 \%$ no lote 1 e $1 \%$ no lote 2 , corroborando os dados de Popay (1974), que obteve 3\% de germinação após 28 dias de teste em condições semelhantes, contra $51 \%$ a $30{ }^{\circ} \mathrm{C}$.

Conclui-se deste estudo que a germinação das sementes da erva-de-touro foi maior nas temperaturas de 25,30 e $35{ }^{\circ} \mathrm{C}$, atingindo valores superiores a 90\%, sendo mais rápida a $30{ }^{\circ} \mathrm{C}$ e mais bem distribuída no tempo a $35{ }^{\circ} \mathrm{C}$. Nas temperaturas de 15,20 e $40{ }^{\circ} \mathrm{C}$ a germinação foi inferior a $6 \%$, com perda de até $80 \%$ na viabilidade das sementes a $40{ }^{\circ} \mathrm{C}$. Em condições não-controladas, a germinação não atingiu $2 \%$.

\section{AGRADECIMENTOS}

Ao professor Júlio Sílvio de Sousa Bueno Filho, do DEX/UFLA, pela contribuição na análise dos dados, e a Cibele Carneiro Fernandes Guimarães, pelo auxilio na preparação, montagem e avaliação dos experimentos.

\section{LITERATURA CITADA}

BACELAR, M. Tridax procumbens L. - Asteraceae Planta daninha de citação recente para o Estado de Minas Gerais. Daphne, v.4, n.2, p.58-61, 1994.

BASKIN, C.C., BASKIN, J.M. Causes of within species variations germination. In: Seeds: ecology, biogeography, and evolution of dormancy and germination. San Diego: Academic Press, 1998. p.181-237.

BEWLEY, J.D., BLACK, M. Seeds: physiology of development and germination 2.ed. New York: Plenum Press, 1994, 445p.

BOTTA, S.M., CABRERA, A.L. Novedades para la flora de Jujuy. Darwiniana, v.27, n.1-4, p.1-8, 1986. 
BROWN, R.F., MAYER, D.G. Representing cumulative germination 2 . The use of the Weibull function and other empirically derived curves. Ann. Bot., v.61, p.127-138, 1988.

CERQUEIRA, E.S. Propagação e calogênese in vitro em erva-de-touro (Tridax procumbens L.), uma planta medicinal. Lavras: UFLA, 1999. 81p. Dissertação (Mestrado em Fitotecnia) Universidade Federal de Lavras, 1999.

EGLEY, G.H. Seed germination in soil: dormancy cycles. In: KIGEL, J.D., GALILI, G. (Eds.) Seed development and germination. New York: Marcel Dekker, 1995. p.529-543.

GUIMARÃES, S.C., FRUTUOSO, L.C. Levantamento das plantas daninhas na cultura da soja, relatório de projeto de pesquisa. Cuiabá: EMPA-MT, 1983. 5p.

HOLZNER, W., HAYASHI, I., GLAUNINGER, J. Reproductive strategy of annual agrestals. In: HOLZNER, W., NUMATA, M. (Eds.) Biology and ecology of weeds. The Hague: Dr W. Junk Publishers, 1982. p.111-121.

KARSSEN, C.M., BOUWMEESTER, H.J. Annual dormancy patterns of weed seeds influence weed control. In: INTERNATIONAL WEED CONTROL CONGRESS, 1, 1992, Melbourne. Proceedings... Melbourne: Weed Science Society of Victoria, 1992. p.98-104.

KISSMANN, K.G., GROTH, D. Plantas infestantes e nocivas. São Paulo: BASF Brasileira, 1992. 797p. t.II; Tridax procumbens L.

LORENZI, H. Plantas daninhas do Brasil. 2. ed. Nova Odessa: Plantarum, 1991. 440p.

MAGUIRE, J.D. Speed of germination-aid in relation evaluation for seedling emergence vigor. Crop Sci., v.2, n.2, p.176-177, 1962.

MARKS, M.K., AKOSIM, C. Achene dimorphism and germination in three composite weeds. Trinidad: Trop. Agric., v.61. n.1, p.69-73, 1984.

MEAD, R., CURNOW, R.N. Statistical methods in agriculture and experimental biology. London: Champman and Hall, 1983. 335p.

POPAY, A.I. Investigations into the behaviour of the seeds of some tropical weeds. I. Laboratory germination tests. East. Afr. Agric. For. J ., v.39, n.1, p.31-43, 1974 .
POPAY, A.I. Investigations into the behaviour of the seeds of some tropical weeds. II. Dry soil storage and seasonal germination. East. Afr. Agric. For. J ., v.40, n.4, p.409-415, 1975.

POPAY, A.I. Investigations into the behaviour of the seeds of some tropical weeds. III. Patterns of emergence. East. Afr. Agric. For. J ., v.41, n.4, p.304-312, 1976.

RAMAKRISHNAN, P.S., JAIN, S. Mineral uptake by three edaphic ecotypes in Tridax procumbens $\mathrm{L}$. Proc. Nat. Inst. Sci. India - Part B Biol. Sci., v.31, n.5/6, p.219-228, 1965 (recd 1966). In: Biol. Abstr., v.48, n.11, 1967. (Abst. 52826.)

SARAF, S., DIXIT, V.K., TRIPHATI, S.C., PATNAIK G.K. Hepatoprotective activity of Tridax procumbens. Part III. Fitoterapia, v.53, n.5, p.414-416, 1992.

SAS Institute. SAS technical report SAS / STAT software: changes and enhancement release 6.07. Cary: 1992.

SHARMA, B.M. Preliminary ecological studies on lithophytes and chasmophytes in South-West Nigeria. Malaysian For., v.50, n.4, p.391-402, 1987.

SHETTY, S.V.R., SIVAKUMAR, M.V.K., RAM, S.A. Effect of shading on growth of some common weeds of the semi-arid tropics. Agron. J ., v.74, p.1023-1028, 1982.

UDUPA, S.L., UDUPA, A.L., KULKARNI, D.R. Influence of Tridax procumbens on lysyl oxidase activity and wound healing. Planta Med., v.57, n.4, p.325-327, 1991.

VERMA, R.K., GUPTA, M.M. Lipid constituents of Tridax procumbens. Phytochemistry, v.27, n.2, p.459-463, 1988.

WULFF, R.D. Environmental maternal effects on seed quality and germination. In: KIGEL, J.D., GALILI, G. (Eds.) Seed development and germination. New York: Marcel Dekker, 1995. p.491-505.

ZIMDAHL, R.L. Where are the principal exotic weed pests? In: WILSON, C.L., GRAHAM, C.L. (Eds.) Exotic plant, pests and North American agriculture. New York: Academic Press, 1983. p. 183-217. 